\title{
ENTREVISTA COM JORGE ALBERTO ALARCÓN-LEIVA, POLÍTICA E EDUCAÇÃO
}

Jémerson Quirino de Almeida ${ }^{1}$

Jorge Alberto Alarcón-Leiva atua como professor e investigador no Instituto de Investigação e Desenvolvimento Educacional (IIDE), na Universidade de Talca, Chile. Concluiu seus estudos de doutorado em Filosofia pela Pontifícia Universidade Católica do Chile em 2008. Realizou o mestrado em Filosofia pela Universidade de Concepción, Chile (1994). Nesta mesma instituição licenciou-se em Educação e Filosofia (1989). Desenvolve pesquisas na área de Educação, com ênfase em Políticas Educacionais, atuando principalmente nos temas ligados ao sistema educativo, a escolarização, a democracia dos acordos, capacidades profissionais e inclusão escolar.

Sua experiência como docente e pesquisador se deu em um país cuja educação passou a partir da década de 1980, de sistema público e gratuito, para o sistema sincronizado com a visão neoliberal de educação. Atualmente, mais de dois terços de toda a educação no Chile está nas mãos da iniciativa privada.

No final do ano de 2016, o professor Jorge Alberto Alarcón-Leiva esteve no Brasil, ministrou palestras em Ponta Grossa - PR e em Campo Grande - MS. Nessa ocasião, nas dependências da UFMS em Campo Grande, conversamos com o professor Arlacón-Leiva e propomos a entrevista. $\mathrm{Na}$

\footnotetext{
1 Professor de História da rede pública de educação do estado de São Paulo e da Universidade estadual de Mato Grosso do Sul (UEMS), pós-graduando no programa de doutorado em educação da Universidade Federal de Mato Grosso do Sul (UFMS), Bolsista CAPES. E-mail: jemersonalmeida@yahoo.com.br
} 
presente entrevista instigamos o professor a falar um pouco mais sobre o sistema educacional chileno e, procuramos desenvolver questões relacionadas com a educação brasileira. Suas considerações nos ofereceu valiosas lições, que podem nos ajudar a compreender os desafios e as incertezas vivenciadas pela nossa educação.

Jémerson Almeida: Pode nos falar sobre sua formação, trajetória na pesquisa e educação?

Jorge A. Alarcón-Leiva: Estudié pedagogía en filosofía, originalmente. Y seguí estudiando filosofía durante mis estudios de postgrado, incluyendo el doctorado. Una vez en la actividad académica, paulatinamente me fui acercando a los problemas educativos. Primero en cuanto a la formación de profesores y profesoras, luego en relación con las cuestiones curriculares de la formación y, finalmente, en los últimos años, en asuntos referidos a la política educativa, al sistema educativo en su conjunto y sus actores.

J. A: Em co-autoria com alguns autores o senhor publicou artigos que analisam os resultados das mudanças na organização educacional chilena nas últimas três décadas. De modo a aproximar nosso leitor a essa produção, poderia em algumas palavras nos apresentar a substância destes textos.

J. A-L: Se trata de trabajos en los que yo mismo -junto con algunos colegasintento explicarme cómo habíamos llegado a la situación actual. Esa era en parte la motivación. Luego, su contenido se refiere a las muchas formas en que 
el sistema educativo ha acompañado las transformaciones acontecidas en Chile. Esas transformaciones han sido institucionales, económicas y normativas. Se logran identificar bien; lo que resulta más difícil saber es cuán coherentemente tuvieron lugar todas ellas. Y esta era la segunda motivación: la intención de identificar algún hilo conductor que diera sentido a las profundas transformaciones que han afectado a Chile.

J.A: Qual foi a postura dos intelectuais chilenos, frente às profundas mudanças promovidas no sistema educacional, que incorporou um modelo de aspiração neoliberal com múltiplos responsáveis pela educação, a partir da década de 1980 no Chile?

J. A-L: Es una excelente y muy problemática pregunta. Es difícil evaluar responsablemente -objetivamente, como se dice- la posición de los intelectuales frente a los cambios. Especialmente difícil es porque los cambios aludidos conectan indirectamente con las simpatías y antipatías generadas por la dictadura cívico-militar. Una dictadura que contó siempre con la participación, entre otros muchos sectores civiles, la complicidad de los propios intelectuales.

No obstante, me parece evidente que los intelectuales llegamos tarde a estos procesos, es decir, logramos explicarnos algunas de las cosas que estaban ocurriendo solo luego que ya estaban no solo instaladas, sino que, en algunos casos, consolidadas. Las mudanzas experimentadas desde los años 80 en Chile han constituido una "pedagogía lenta", cuya enseñanza ha sido muy dolorosa 
$\mathrm{y}$, en muchos casos, triste. Pienso que en los últimos años se ha venido produciendo una cierta sincronía entre los intelectuales y, digamos, la calle; es decir, entre las formas en que los intelectuales explicamos los hechos y la población, que se ha manifestado masivamente desde muy al comienzo de los cambios.

J. A: Em palestra proferida na UFMS/Brasil o senhor falou sobre a situação político-social chilena (ditadura civil-militar e terremoto em 1985) e a relação desse momento catastrófico da história do país com as mudanças promovidas na educação. Em sua opinião a utopia economicista em curso no Chile, não levou em conta a força contra-hegemônica do povo chileno, como a demonstrada no Movimento Pinguino de 2006?

J. A-L: De nuevo, esta es una pregunta que no se responde con un "sí" o con un "no", vale decir, su respuesta no es simple. No lo es porque no se trata de una oposición tan fuerte entre una fuerza hegemónica y otra contrahegemónica. Las diferencias entre las fuerzas son harto más complejas, por sutiles. Yo pienso que ello se debe en parte a la consigna que pone la calidad de la educación como una demanda que tiene el mismo estatus que la exigencia del derecho a educación. Es decir, se debe a la convivencia entre un objetivo de gestión empresarial y otro de carácter político, al mismo nivel.

Entonces, se ha exigido "educación pública, gratuita y de calidad", como si todo perteneciera a una misma tesitura, como si fueran todas estas demandas del mismo paño. No es el caso: de hecho, me parece que la exigencia por la 
calidad es un "préstamo" de la retórica neoliberal a la "retórica política". Esta última retórica, aceptó a-críticamente tal préstamo y no ha podido darle un sentido congruente al conjunto de la demanda. Se trata de intentar conciliar el "gerenciamiento" con el sector público. En mi parecer, hay que examinar algo más profundamente que la sola textura discursiva de las fuerzas que están en juego, para comprender la forma en que unas se entrecruzan con otras. Esto no quiere decir que el discurso o la narrativa de dichas fuerzas no sea relevante, sino que hay que mirar con mayor detalle su despliegue.

J. A: Acreditamos que a organização do trabalho didático na escola contemporânea pauta-se na relevante função atribuída aos livros escolares. Essa foi uma das propostas centrais do capitalismo para a escola moderna, consubstanciada em Comenius, no séculoXVII. No Brasil, os livros escolares são considerados os principais elementos do trabalho didático nas escolas. No Chile o livro escolar também exerce protagonismo na educação básica?

J. A-L: Sí, claro, también en Chile. El que así sea, no debiera sorprendernos, por otra parte. Se ha tratado de un programa histórico de los procesos de modernización de las instituciones educativas en Europa y, por cierto, también en América Latina, cuestión natural so se atiende a nuestra relación de dependencia cultural. Ha sido parte del beneficio, pero también parte del lastre, digamos, que nuestra educación ha debido arrastrar desde la constitución de las naciones americanas, que es otra herencia europea -la idea de "Nación", digo. En todo caso, me parece que en nuestros países la situación de sugerentemente distinta. A causa del fenómeno que autores como Lezama 
Lima han llamado "neobarroco", uno puede adelantar una hipótesis sobre el fenómeno de mestizaje que estas prácticas adoptan en la realidad de nuestros países, por mucho que algunos de ellos parezcan "más modernos", por "más europeos", que otros; o, inversamente, que algunos parezcan "menos desarrollados" que otros.

Quiero decir que se trata de unas prácticas en cuya realización conviven lo antiguo y lo moderno, produciéndose una tensión entre conservación de la tradición e innovación transformadora que no termina de resolverse en una $\mathrm{u}$ otra de esas direcciones, en dirección de lo viejo o de lo nuevo, digamos.

El aula es así un "presente tenso", por darle algún nombre a ese fenómeno de convivencia de direcciones opuestas que tiene lugar con el uso privilegiado del libro en contextos que, desde muy antaño, reniegan del autor, del genio individual, de la revelación, de la lectura y de una cultura de la vista, como la que supone el uso de los textos escolares como mecanismos de socialización fundamental en las escuelas básicas.

J.A: A educação no mundo capitalista se converteu numa mercadoria cada vez mais valiosa. No artigo El lucro en la educación chilena: debate conceptual acerca del sentido de la educación pública y de la privada escrito em parceria com Sebastián Donoso-Díaz, os senhores afirmam que: "Ser parte de un proceso educativo implica la adhesión a una forma de vida en la que los individuos, pudiendo estar en desigual posición, disponen de una herramienta para restituir la simetría que es exigida por la igual dignidad de todos". Com base 
nesse princípio, por quais meios podemos trilhar um caminho educativo de qualidade que viabilize equilibrar as práticas sociais?

J. A-L: No sabría decir si el citado es un "principio", pero de serlo uno podría preguntar con cierto escepticismo, ¿cómo se hacen cosas con principios?", que me parece que no es otra cosa que decir algo como aquello de que "lo que vale en teoría, no vale en práctica". Es decir, una expresión del descrédito de la teoría y del valor atribuido a la práctica, a la experiencia y a la utilidad, como baremo que establece lo que debe importarnos y lo que no debe importarnos.

En fin, la cuestión es que lo que se dice ahí, en el texto aludido, no es un deberser, algo que no es y que debiera ser; es, antes bien, una descripción acerca de cómo entendemos la educación, vale decir, un mecanismo, un dispositivo social que reestablece $\mathrm{o}$, más precisamente, que ayuda a reestablecer las inequidades de origen de las personas. Esta restitución es normativa, eso sí, en cuanto deriva del hecho que las personas tenemos la misma dignidad que implica mismo trato.

J.A: O Brasil passa hoje por um intenso debate (debate esse que só teve início por conta da postura contra-hegemônica de professores e alunos, que não aceitaram passivamente as imposições do governo) sobre possíveis mudanças no sistema educacional. Tais mudanças vão desde a reforma curricular do ensino médio, à proposta de emenda constitucional (PEC 241, rebatizada no senado de PEC 55) que busca limitar os gastos públicos em diversas áreas, incluindo a educação. Com base nas experiências educacionais vivenciadas 
pelo Chile, em sua opinião, quais desdobramentos são possíveis de ser previstos, caso essas medidas do governo brasileiro em relação à educação, sejam efetivadas?

J. A-L: Mi parecer al respecto es que, tal como dichas medidas son descritas, por el contexto y la orientación al interior de las cuales tienen lugar, debieran describir una especie de fase preparatoria para la privatización del sector. Los efectos de la privatización educativa, en virtud de la hegemonía neoliberal en buena parte de América Latina, son relativamente conocidos y ellos se orientan a generar algo que se opone a lo que se describía antes, en cuanto a igualdad de trato por igual dignidad.

Los sistemas educativos con grados mayores de privatización son, en general, cada uno con sus particularidades, desiguales en el trato porque suponen que los individuos no estamos todos en condiciones de recibir lo mismo, aunque esta diferencia pudiera no basarse necesariamente en desigualdades económicas, si no que, en diferencias de mérito, por ejemplo.

J.A: Segundo o pesquisador brasileiro Ivo Tonet "uma concepção de educação está vinculada ao tipo de sociedade que se deseja construir, o que inclui todo o conjunto de concepções a respeito do homem, da sociedade e da história". Frente às políticas educacionais em curso atualmente na América Latina, que tipo de sociedade o senhor acredita, que nós latino-americanos, podemos construir? 
J. A-L: Estoy de acuerdo, a despecho que el vínculo entre un cabo y otro de una hebra tan extensa sea difícil de establecer. La educación es, para decirlo con una metáfora procedente de D. Hume, el cemento de la vida social. En este sentido, educar es una cuestión tan especialmente sensible que de ella puede decirse que depende la forma que le damos al agua. Vale decir, de la educación depende la forma que tiene el orden social para nosotros e, inclusive, la educación es la razón que motiva a hablar de "nosotros". De modo que, de hecho, uno podría radicalizar la pregunta diciendo que hay al menos una forma conocida, la forma neoliberal, de acuerdo con la cual esa pregunta no tiene sentido. No lo tiene porque para el neoliberal la sociedad no existe, no existe un nosotros, sino que solo individuos, como lo dijera en su momento Thatcher. Justamente a comienzos de los años ochenta.

Recebido: 26 de abril de 2017

Aceito: 27 de abril de 2017

Publicado: 10 de maio de 2017 